\title{
Study of Antimicrobial Sensitivity Pattern of Bovine Mastitis using Various Tea Extracts
}

\section{Susmita Sethi ${ }^{1}$, Rajashree Mishra ${ }^{1}$, Kautuk Kumar Sardar ${ }^{2}$, Kailash Singh Bisht ${ }^{1}$, Iswar Anand Senapati ${ }^{*}$, Prasana Kumar Rath ${ }^{3}$ and Bidyut Prava Mishra ${ }^{4}$}

${ }^{1}$ Department of Veterinary Microbiology, ${ }^{2}$ Department of Veterinary Pharmacology \& Toxicology, ${ }^{3}$ Department of Veterinary Pathology, ${ }^{4}$ Department of Livestock Products Technology, College of Veterinary Science and Animal Husbandry, OUAT, Bhubaneswar, India

*Corresponding author

\section{Ke y w o r ds}

Bovine mastitis,

Tea extract,

Antimicrobial activity, Camellia sinensis

Article Info

Accepted:

10 September 2019

Available Online:

10 October 2019

\section{A B S T R A C T}

In the present study 105 numbers of microbial isolates were isolated from 96 milk samples and were processed as per routine method of microbial isolation. Various types of tea extracts like black tea and green tea were used in combination with antibiotic discs obtained from HiMedia, Mumbai. The synergistic effects of antibiotics and tea extracts against resistant bovine pathogens lead to new choices for development of combination therapy during chronic mastitis. In the present study methanol was used as solvent for green and black tea samples in various concentrations. It is revealed that the tea extracts in combination with chloramphenicol, tetracycline, levofloxacin and gentamicin enhanced the zone of inhibition in comparison to individual therapy. In order to establish the above finding a more elaborative study on mastitogenic microbial isolates the antimicrobial synergistic testing is needed.

\section{Introduction}

The incidence of clinical and subclinical mastitis in cross bred cows is a common problem for coastal and remote areas of Odisha in summer season. Bovine mastitis is an inflammatory condition of mammary gland most often caused by bacterial intramammary infection.The principal pathogens causing mastitis are pathogenic Staphylococcus spp. and Streptococcus spp. (Boonyayatraet al., 2014). It adversely affects milk production and causes widespread economic losses. The subclinical mastitis has been 15 -40 times more 
prevalent than the clinical mastitis (Sudhan and Sharma,2010).And controlling subclinical mastitis can substantially reduce $75 \%$ of economic losses in milk production (Constable et al., 2017).

Clinical and subclinical cases of mastitis are routinely treated with antimicrobial therapy both intramammary and parenterally. The use of antimicrobials over long period has triggered the development of multidrug resistant strains, which has resulted in the use of increasing dose of antimicrobials, causing the danger of increasing amount of drug residues in the milk, a potential biohazard (Dhanabalan et al., 2008). In some MDR cases, the use of combination of the antibiotic drugs with different bioactive compounds is the possible option for the treatment (Bag and Chattopadhyay, 2015). The combination therapy of antibiotics and herbs or beverages can be used to improve the antimicrobial spectrum, to prevent the emergence of the resistant mutants, to minimize toxicity and to obtain synergistic antimicrobial activity (Pankey and Ashcraft, 2005). Some studies (Braga et al., 2005, Dickson et al., 2006 and Gibbons et al., 2003) have reported that plant extracts can increase the in-vitro activity of antibiotics against MDR strains of Staphylococcus aureus and other pathogens.

Tea extract from the leaves of plant Camellia sinensis has been shown to have wide range of antioxidant, anti-inflammatory, anticarcinogenic and antibacterial activity against many pathogens (Hamilton-miller, 1995). This antimicrobial activity of the tea extract is due to the presence of active ingredient catechin mainly epigallocatechingallate, EGCG (Song and Seong, 2007).

In the present study, antibiogram study of field isolates and evaluation of antimicrobial effects of tea (Camellia sinensis) extracts on bovine Mastitogenic isolates was conducted.

\section{Materials and Methods}

\section{Sample collection}

In this study a total of 96 milk samples were obtained from TVCC of C.V.Sc. \& A.H. Bhubaneswar, A.D.R.I. Phulnakhara and other organized dairy farms. The milk samples were collected aseptically from the affected quarter and found positive for mastitis through Modified Californian Mastitis Test.

\section{Bacterial isolation and identification}

The isolation of the bacteria was done by growth on selective media. The selective media used were Mannitol Salt Agar for Staphylococci, Edwards' Modified Blood Agar for Streptococci (Buxton and Fraser, 1977), Pseudomonas Isolation Agar for Pseudomonas spp. (Figure 1). The test isolates were then identified by various biochemical and sugar fermentation tests. For the isolation and identification of Enterobacteriaceae the method outlined by Edwards and Ewing (1972) was followed (Figure 2 and 3). The biochemical tests performed to identify the isolates were Indole, MR, VP, Citrate utilization test, $\mathrm{H}_{2} \mathrm{~S}$ production test (Cruickshank et al., 1980). And hemolysis, coagulase test (Merchant and Packer, 1967) and motility test were also performed.

\section{Preparation of antibiotic and tea discs}

The detail procedure of Esimoneet al., (2003) was followed with slight modification. According to the procedure circular filter paper discs $(6 \mathrm{~mm}$ diameter) were prepared with the aid of an office paper perforator. The discs were placed in a petri dish and sterilized in an autoclave. Solutions of the methanolic tea extract of different concentrations $(5,10$, $15,25,30,35,40,45,50 \mathrm{mg} / \mathrm{ml})$ and a suitable antibiotic were made in different test tubes. The paper discs were then aseptically 
transferred into the tubes containing the drugs' solutions and allowed to absorb the solution for about 15 seconds. The discs were then aseptically transferred to empty sterile tubes and allowed to air dry while the mouth of the test tube is still plugged with cotton wool.

Each of the test tubes containing the dried discs was well labelled with the strength of the solution of the drug in which the paper discs were dipped. It had been established that the $6 \mathrm{~mm}$ disc has a capacity of absorbing $10 \mu \mathrm{l}$ of drug solution at saturation.

\section{Antibacterial susceptibility test}

The antibacterial activity of various antibiotics against the mastitogenic isolates obtained were assayed by disk diffusion method according to Bauer et al., (1996) and zone of inhibition is recorded. For the test Mueller Hinton Agar Media (HiMedia, Mumbai) was used.

The antibiotics discs used were Tetracycline (30 mcg), Ampicillin (10 mcg), Neomycin (30 $\mathrm{mcg}$ ), Erythromycin $(15 \mathrm{mcg})$, Penicillin (10 units), Ciprofloxacin (5 mcg), Gentamicin (10 $\mathrm{mcg}$ ) and Doxycycline (30 $\mathrm{mcg})$. The antibiotic discs were obtained from HiMedia, Mumbai.

In order to know the combined effects of the antibiotics along with methanolic tea extracts, the above prepared discs were used (Figure 4).

\section{Results and Discussion}

In this study, a total of 105 bacterial isolates were recovered from 96 milk samples. The predominant isolates recovered were Staphylococcus aureus and Escherichia coli followed by Streptococcus spp., Klebsiella spp. and Pseudomonas spp. It was revealed that $85 \%$ of Coliform spp. Isolates were highly sensitive to Gentamicin. For Streptococcus spp. tetracycline was found to be $75 \%$ sensitive like was for Staphylococcus spp. Ciprofloxacin (75\%) for Proteus spp. Tetracycline (70\%), for Corynebacterium spp. both the antibiotics Ampicillin (86.5\%) and Ciprofloxacin $(85 \%)$ respectively (Table 1$)$.

The crude methanolic extract of green tea and black tea when mixed with Chloramphenicol showed good results at the concentrations of $25-50 \mathrm{mg} / \mathrm{ml}$ but it gave poor results at other lower concentrations.

The synergistic activity of crude methanolic extracts of green tea and black tea in combination with Levofloxacin, Tetracycline and Gentamicin showed best activity against Staphylococcus aureus at all concentrations (Table 2). The synergistic combination showed better results as compared to the green tea and black tea alone.

This study has shown that crude extract of the leaves of Camellia sinensis exhibits potentials of synergy in combination with some antibiotics against pathogenic bacteria often presenting problems of drug resistance.

Such synergistic attributes of crude extracts of Camellia sinensis leaves and antibiotics demonstrates that this plant possesses antibiotic resistance modifying compounds.

It is concluded that tea extract did not impair the antimicrobial properties of antibiotics; rather, it enhanced its activity in an additive manner which could be beneficial in the treatment of staphylococcal infections. The synergistic effect from the association of antibiotic with tea extracts against resistant bacteria leads to new choices for the treatment of mastitis. 
Table.1 Sensitivity pattern of bacterial isolates that was isolated from mastitic cows to different antibiotics

\begin{tabular}{|c|c|c|c|c|c|c|}
\hline Antibiotics & Dose & $\begin{array}{c}\text { Coliform } \\
\text { spp. }\end{array}$ & $\begin{array}{c}\text { Strepto. } \\
\text { spp. }\end{array}$ & $\begin{array}{c}\text { Staph. } \\
\text { spp. }\end{array}$ & $\begin{array}{c}\text { Proteus } \\
\text { spp. }\end{array}$ & $\begin{array}{c}\text { Corynebacterium } \\
\text { spp. }\end{array}$ \\
\hline Tetracycline(T) & $30 \mathrm{mcg}$ & $52.5 \%$ & $75 \%$ & $71.8 \%$ & $70 \%$ & $85 \%$ \\
\hline Ampicillin(A) & $10 \mathrm{mcg}$ & $3 \%$ & $69 \%$ & $79 \%$ & $0 \%$ & $86.5 \%$ \\
\hline Neomycin(N) & $30 \mathrm{mcg}$ & $12 \%$ & $13.5 \%$ & $24.6 \%$ & $11.5 \%$ & $12.5 \%$ \\
\hline Erythromycin(E) & $15 \mathrm{mcg}$ & $9 \%$ & $81 \%$ & $34 \%$ & $49 \%$ & $60.5 \%$ \\
\hline Penicillin G(P) & $10 \mathrm{units}$ & $3 \%$ & $54.4 \%$ & $72 \%$ & $0 \%$ & $80 \%$ \\
\hline Ciprofloxacin(CF) & $5 \mathrm{mcg}$ & $73 \%$ & $70 \%$ & $75 \%$ & $25 \%$ & $85 \%$ \\
\hline Gentamicin(G) & $10 \mathrm{mcg}$ & $85 \%$ & $60 \%$ & $65 \%$ & $15 \%$ & $75 \%$ \\
\hline Doxycycline(DO) & $30 \mathrm{mcg}$ & $12 \%$ & $10 \%$ & $13 \%$ & $29 \%$ & $11 \%$ \\
\hline
\end{tabular}

Table.2 Synergistic Antibacterial activity of crude methanolic extract of green tea and black tea samples with Chloramphenicol, Tetracycline, Levofloxacin and Gentamicin antibiotics

\begin{tabular}{|c|c|c|c|c|c|c|c|c|c|}
\hline \multirow{3}{*}{$\begin{array}{l}\text { Sl. } \\
\text { No. }\end{array}$} & \multirow{3}{*}{$\begin{array}{l}\text { Conc. } \\
(\mathrm{mg} / \mathrm{ml})\end{array}$} & \multicolumn{8}{|c|}{ Zone of inhibition $(\mathrm{mm})$ of green and black tea } \\
\hline & & \multicolumn{2}{|c|}{ Chloramphenicol } & \multicolumn{2}{|c|}{ Tetracycline } & \multicolumn{2}{|c|}{ Levofloxacin } & \multicolumn{2}{|c|}{ Gentamicin } \\
\hline & & $\begin{array}{c}\text { Green } \\
\text { tea }\end{array}$ & $\begin{array}{c}\text { Black } \\
\text { tea }\end{array}$ & $\begin{array}{c}\text { Green } \\
\text { tea }\end{array}$ & $\begin{array}{c}\text { Black } \\
\text { tea }\end{array}$ & $\begin{array}{c}\text { Green } \\
\text { tea }\end{array}$ & $\begin{array}{c}\text { Black } \\
\text { tea }\end{array}$ & $\begin{array}{c}\text { Green } \\
\text { tea }\end{array}$ & $\begin{array}{c}\text { Black } \\
\text { tea }\end{array}$ \\
\hline 1 & 5 & - & 12 & 16 & 15 & 17 & 18 & 14 & 15 \\
\hline 2 & 10 & - & - & 18 & 18 & 17 & 18 & 16 & 16 \\
\hline 3 & 15 & - & - & 17 & 16 & 13 & 12 & 14 & 12 \\
\hline 4 & 20 & - & - & 19 & 17 & 18 & 17 & 15 & 15 \\
\hline 5 & 25 & 14 & 13 & 16 & 18 & 18 & 19 & 16 & 14 \\
\hline 6 & 30 & 13 & 12 & 17 & 15 & 16 & 15 & 16 & 15 \\
\hline 7 & 35 & 17 & 15 & 18 & 18 & 17 & 18 & 17 & 16 \\
\hline 8 & 40 & 17 & 15 & 16 & 16 & 19 & 19 & 17 & 15 \\
\hline 9 & 45 & 15 & 14 & 16 & 17 & 19 & 19 & 18 & 16 \\
\hline 10 & 50 & 18 & 17 & 19 & 18 & 19 & 18 & 19 & 18 \\
\hline
\end{tabular}

Fig.1 Pseudomonas sp. colonies on Pseudomonas Isolation Agar (PIA)

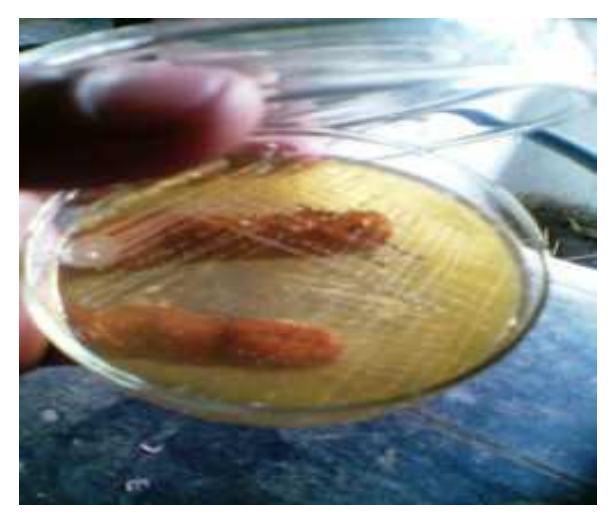


Int.J.Curr.Microbiol.App.Sci (2019) 8(10): 883-889

Fig.2 E. coli colonies on MacConkey Lactose Agar (MLA)

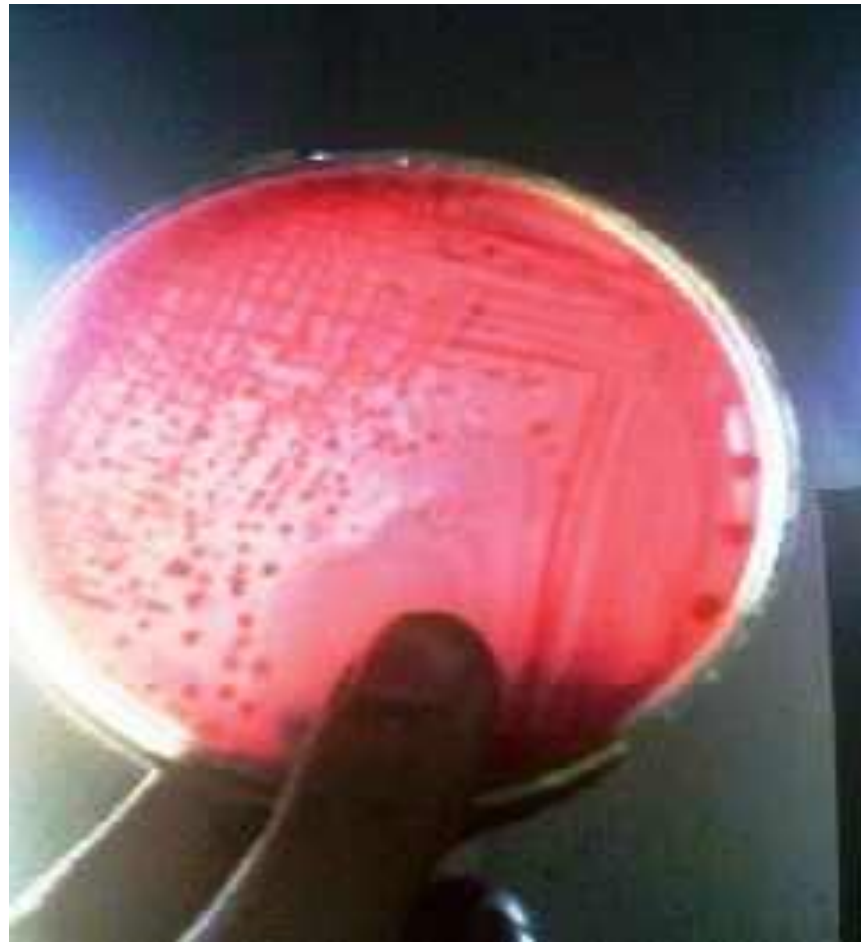

Fig.3 E. coli colonies grown on EMB Agar

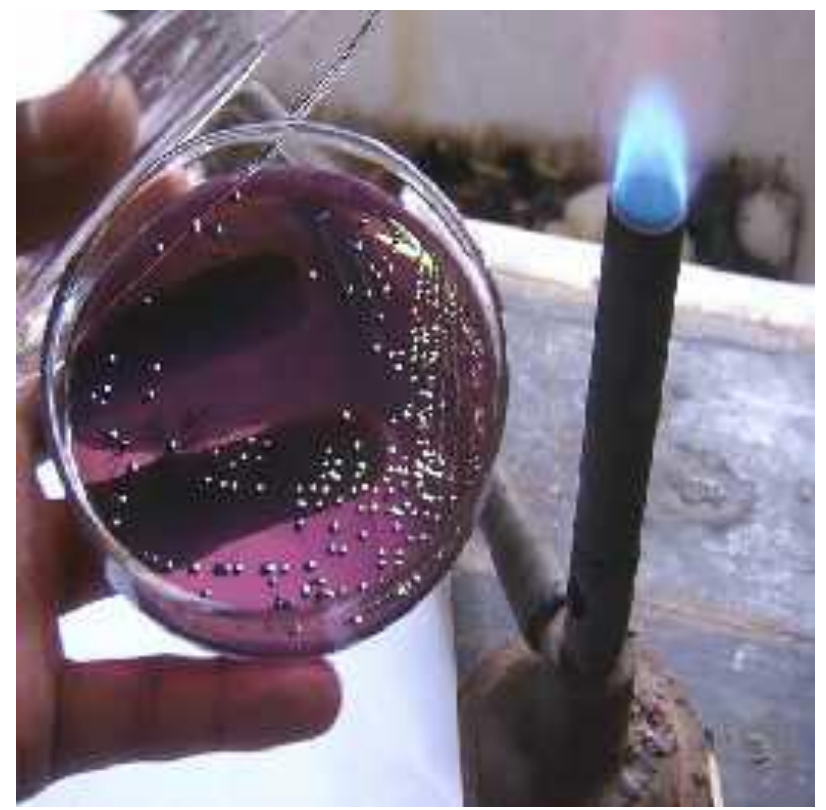


Fig.4 Zone of inhibition against Staphylococcus aureus using combination of tea extract at different concentration with antibiotics

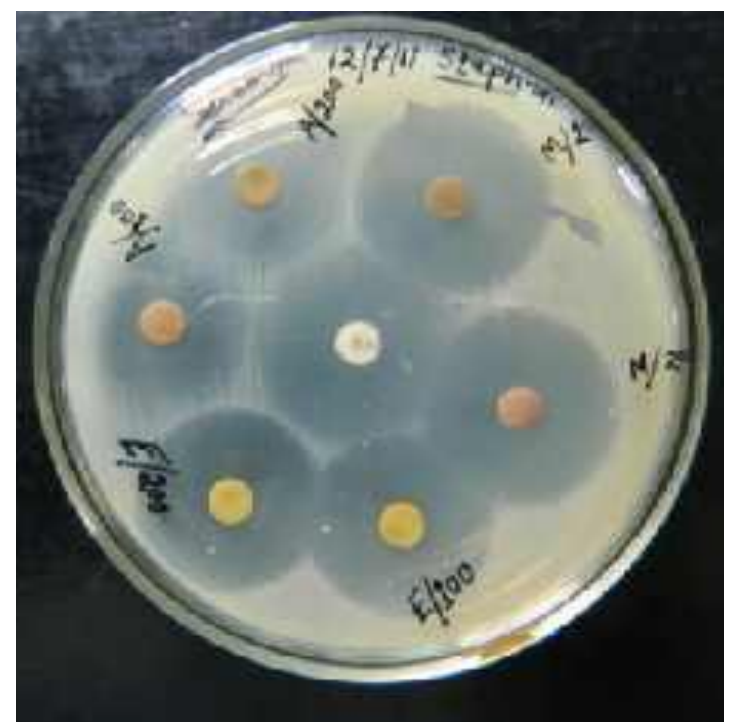

\section{References}

Bag, A., and Chattopadhyay, R.R. 2015. Evaluation of synergistic antibacterial and antioxidant efficacy of essential oils of spices and herbs in combination. PLoS One 10(7), e0131321.

Bauer A.W., Kirby W.M.M., and Sherris J.C. 1996. Antibiotic susceptibility testing by a standardized single disk method. American Journal of Clinical Pathology, 45: pp: 493-496.z

Boonyayatra, S., Rin-ut, S., and Punyapornwithaya, $\quad$ V. 2014. Association of intramammary infection caused by Biofilm- producing pathogen with chronic mastitis in Dairy cows. International Journal of Dairy Science. 9(3): 89-95.

Braga, L.C., Leite, A.A.M., Xavier, K.G.S., Takahashi, J.A., Bemquerer, M.P., Chartone-Souza, E., and Nascimento, A.M.A. 2005. Synergic interaction between pomegranate extract and antibiotics against Staphylococcus aureus. Can. J. Microbiol. 51: 541-547.

Buxton, A., and Fraser. G.1977.Animal
Microbiology, Vol. I, Blackwell scientific Publications Ltd., Oxford, London.

Constable, P. D., Hinchcliff, K. W., Done, S. H., and Grunberg, W. 2017. Veterinary Medicine. $9^{\text {th }}$ edition. Elsevier Ltd. St. Louis, Missouri.

Crickshank, R., Duguid, J.P., Marmion, B.P., and Swain, R.H.A. 1980. Medical Microbiology. Twelfth Ed. Vol. II Churchill, Livingstone London.

Dhanabalan, R., Doss, A., Jagadeeswari, M., Balachandar, S., and Kezia, E. 2008. In vitro Phytochemical Screening and Antibacterial Activity of Aqueous and Methanolic Leaf Extracts of Tridax procumbens against Bovine Mastitis Isolated Staphylococcus aureus, Ethnobotanical Leaflets 12: 1090-95.

Dickson, R.A., Houghton, P.J., Hylands, P.J., and Gibbons, S. 2006. Antimicrobial, resistance-modifying effects, antioxidant and free radical scavenging activities

of

Mezoneuronbenthamianum Baill, Securinegavirosa Roxb. and Wlld. And Microglossapyrifolia Lam. Phytother Res. 20:41-45. 158. 
Edwards, P.R., and Ewing, W. 1972. Identification of Enterobacteriaceae I. 3Ed. Burgess Pub. Co.

Esimone, C.O., Adikwu, M.U., Ndu, O.O., Udeogaranya, P.O., Ezeugwu, C.O., and Obonga, W. 2003. Effect of Garcinia kola seed extract on the antimicrobial properties of some antibiotics in-vitro. J. Pharmaceutical \& Allied Sci. 2: 114-120.

Gibbons, S., Fallah, F., and Wright, C. W.2003.Cryptolepine hydrochloride: a potent antimycobacterial alkaloid derived from Cryptolepis sanguinolenta. Phytother. Res. 17:434-436.

Hamilton-Miller, J.M. 1995. Antimicrobial properties of tea (Camellia sinensis L.). Antimicrob Agents Chemother.
39: 2375-7.

Merchant, I. A., and Packer, R.A.1967. Veterinary Bacteriology and Virology, $7^{\text {th }}$ Ed., The Iowa State University Press. Iowa, U.S.A.

Pankey, G., Ashcraft, D., and Patel, N.2005. In vitro Synergy of Daptomycin plus Rifampin against Enterococcus faecium Resistant to both Linezolid and Vancomycin. Antimicrob. Agents Chemother., 49:5166-5168.

Song, J.M., and Seong, B.L. 2007. Tea catechins as a potential alternative anti-infectious agent. Expert Rev. Anti-infect. Ther. 5 (3), 497-506.

Sudhan, N.A. and Sharma, N. 2010. MastitisAn important production disease of dairy animal, SMVS Dairy Year Book. Pp.72-88.

\section{How to cite this article:}

Susmita Sethi, Rajashree Mishra, Kautuk Kumar Sardar, Kailash Singh Bisht, Iswar Anand Senapati, Prasana Kumar Rath and Bidyut Prava Mishra. 2019. Study of Antimicrobial Sensitivity Pattern of Bovine Mastitis using Various Tea Extracts. Int.J.Curr.Microbiol.App.Sci. 8(10): 883-889. doi: https://doi.org/10.20546/ijcmas.2019.810.102 